\title{
Through the Looking Glass: Kraftwerk's Influence on Music Technology \& German Cultural Identity
}

\author{
Scott Shannon \\ University of Houston, Texas, USA \\ scottoshannon@yahoo.com \\ Kyle J. Messick \\ Ivy Tech Community College, Indiana, USA \\ psymessick@gmail.com \\ https://orcid.org/0000-0002-0452-0922
}




\title{
Through the Looking Glass: Kraftwerk's Influence on Music Technology \& German Cultural Identity
}

\begin{abstract}
Although the band Kraftwerk have been extensively noted for their pioneering musical style, what has been given less attention is their broader cultural impact, how they served as a source for German identity in a time of crisis, and the conditions under which their music was formed and changed over time. This article examines their influence through the sense of cultural identity Kraftwerk provided for Germanic peoples post-World War II, their fundamental influence on future musical acts that would incorporate electronics into their music, their innovation in their creation of new musical instruments/technologies, and the application of those instruments in novel performance and recording settings.
\end{abstract}

Keywords: Kraftwerk, krautrock, music technology, Germanic culture, identity

\section{The Emergence of Kraftwerk \& Krautrock}

During the 1960's and 1970's, popular music as a whole experienced an explosion of growth and diversification. With the developments of the progressive rock and industrial scenes in the UK, the jazz fusion scene in the US, and the krautrock/"Berlin School” scenes in Germany, music was undergoing a complete cosmopolitan renaissance heavily rooted in sonic experimentation and pushing musical boundaries in a way that had never been witnessed before. "Krautrock" was the colloquial term used to describe the experimental rock that developed in West Germany in the late 1960s that combined elements of psychedelic rock, electronic music, and a broad range of avant-garde influences. The German krautrock scene specifically brought forth countless innovations. These included the use of early synthesizers; experimental tape-editing techniques such as cutting, splicing, or altering the magnetic tape itself; as well as the forward-thinking use of electronic gear-like drum machines, electronic drum kits, and vocoders (a synthesizer for the human voice). The krautrock scene largely emerged within Germany's youth groups that were actively rebelling against their country's legacy in World War II two decades earlier and were actively seeking to reform their cultural identity, which included through the formation of new musical acts. One of the most influential bands in this cultural movement was Kraftwerk, who formed in 1970 in Düsseldorf. Both Kraftwerk and Can (another influential Krautrock band) provided a sense of postwar cultural identity for Germanic peoples that embraced technological innovations while emphasizing the relationship between man and machine (Adelt). Whereas Can was still rooted heavily in traditional rock instrumentation, Kraftwerk became an all-electronic musical group over time that emphasized their Germanic heritage, making them all the more novel and distinctively a product of Germanic identity. Some scholars have even gone as far as to say that Krafterwerk's popular song 'Autobahn' is a quintessential song that reflects a summative depiction of Germany's newfound 1970s cultural identity communicated through spatialities, temporalities, and subjectivities (Schiller).

Among the many different krautrock bands, Kraftwerk proved to be the most influential both musically and technologically. Musically, Kraftwerk's most distinctive quality is likely their utilization of propulsive, repetitive rhythms. From their very beginning, Kraftwerk refused to let technological limitations hinder their creative vision. They often created or commissioned their own custom-built electronic instruments with their most famous example being the electronic drum pads first used on their 1974 album Autobahn. Additionally, their famous "Kling Klang" private studio more so resembled a sound laboratory where experimentation occurred than any sort of recording studio, and the studio was often treated as a musical instrument itself 
(Schütte). Kraftwerk's lyrics were an area of influential and cultural impact too, as their content often celebrated the monotony of post-war Europe along with the technology that was used in daily life, all with a certain glimmer of hope for the future. Through harnessing their bold, technology-focused vision, they continually pushed towards new, uncharted sonic territories and questioned the roles people and technology took in relation to music composition. This article outlines Kraftwerk's musical development and influence through five areas: 1) the conditions for their formation and their influence on German cultural identity following WWII, 2) their musical influences, 3) their unique financial situation that enabled their musical creation and innovation, 4) their musical and technological evolution, and 5) their influence and legacy seen through current musical acts.

\section{The Germanic Cultural Landscape and Struggles of Identity}

It has often been argued that Kraftwerk can only be fully understood by taking into account the specific social, economic and political context of late 1960s and early 1970s Germany (Cohen). During this time, Germanic youths were pushing against two facets in order to find their own, new identity: 1) The influence of other western cultures on Germanic identity, and 2) the authoritarian association from previous decades. The youth wanted to find a unique Germanic identity that was not borrowed from other Western cultures and they wanted to distance themselves from the authoritarian associations from the previous World War. During the decades following World War II, West Germany received extensive international aid resulting in thousands of US and British troops stationed in the region. This unique overlap motioned in a flood of Anglo-American culture into West Germany. Before citizens realized it, West German radio was dominated by rock ' $n$ ' roll and kids began to pick up English but with American accents (Cope). This pervasion of American and British culture, however, left a vacuum of any tangible German culture for German people to latch on to. As Kraftwerk's Ralf Hütter puts it:

There was really no German culture after the war. Everyone was rebuilding their homes and getting their little Volkswagens. In the clubs when we first started playing, you never heard a German record, you switched on the radio and all you heard was Anglo-American music, you went to the cinema and all the films were Italian and French. That's okay but we needed our own cultural identity (Barr 13).

The other major source of cultural dissonance stemmed from Germany's role in WWII. This was a timeframe when people in Germany were struggling to find meaning and understanding causing widespread protests in Berlin pushing towards a freer democracy. The desperation for German cultural prosperity was further echoed through disgruntled students fed up with the inaction of their government, leading to the 1968 German student movement. In the eyes of most German students, the government had not done nearly enough to move on and distance themselves from its Nazi past with their then chancellor, Kurt Georg Kiesinger, having actually been a member of the National Socialist German Workers' Party during Hitler's reign. This led to violent conflicts between students and police culminating in a battle on February $28^{\text {th }}, 1968$ between 3,000 demonstrators and 1,000 police officers leaving hundreds injured. It was a time of conflict that was perceived as a struggle against authoritarian powers to progress democracy (Della Porta). In addition to this, there was a desire for a new Germanic identity that wasn't adapted from the past or borrowed from the numerous other cultures that had increasing prominence within the country. In the aftermath of WWII, Germany was left with a divided nation of low-spirited citizens, desperate to latch onto new ideas as a means to leave behind their 
sordid past.

The production of art, as well as most other social institutions, was tainted by the Third Reich that dictated over Germany from 1933-1945. This resulted in a desire by Germanic musicians to distance themselves from conventional notions of harmonic structure and melody because those were constructs largely associated with the cultural policies of the Nazi regime (Pattie). As a result, Germanic musicians moved towards avant garde approaches in musical production, both in terms of songwriting and instrumentation. Their desire to progress onward from Germany's past towards a new future coupled with their dissatisfaction with American/British rock tropes became the perfect catalyst for the creation of krautrock as a new, experimental music style unlike anything ever seen or heard before. In the case of Kraftwerk, this simultaneous push against the past as well as forging forward towards a new cultural identity resulted in their unique art style characterized by primarily instrumental music using electronics and extensive song lengths that were free-form in composition. Their music frequently used repetition in place of traditional tonality and scales, often oscillating between simple harmonies and radical divergences especially on their earliest albums.

The subject matter of Kraftwerk's lyrics and aesthetic focused around technology and industry, which can be attributed to the broader social and political climate in West Germany at the time. Having relatable lyrics can serve as a way to help individuals cope and connect (Messick and Aranda; Messick, Aranda, and Chris), so the focus on these monotonous aspects of life offered a connecting point for the struggles that were being experienced. The disillusion with Germany's past caused a cultural 'flatness' in affect and art that also extended to a critical disassociation with politics (Cohen). This cultural state of automaton-like behavior and precedent translated well into the context of music for a new generation of German youth. This is notably exhibited in Kraftwerk's pervasive use of the vocoder throughout most of their career, which mimicked the sound of a robot talking, appearing as early as their 1973 album Ralf and Florian. In fact, Kraftwerk likened themselves to robots and also remained stoic and seemingly unenthusiastic when they would play their music live, going as far as to replace themselves with robots for parts of performances. Kraftwerk were embraced by Germanic youth that were struggling with feelings of dissatisfaction and monotony, and Kraftwerk channeled those feelings into a new art form to which they could relate. Kraftwerk's music might appear a cultural novelty in modern times, but within the context of post-war Germany, they played a fundamental role in providing Germanic youth with a new cultural product that was uniquely German, but that was also not tainted by or in any way associated with the depravities of the past.

\section{Musical Lineage}

Despite popular thinking, krautrock was not necessarily a concrete genre of music but rather a movement composed of like-minded musicians possessing a great insistence on creating something completely new (Brown). This subtle distinction implies that the music itself covers a vast spectrum of different sounds and defies any meaningful categorization. However, even krautrock bands possess a handful of common characteristics including "a reliance on electronic sounds and new musical technology (e.g. synthesizers), extended improvisation, often involving non-Western modalities, emphasis on texture and timbre (sound as such) over composition and connection to the European avant-garde tradition" (Brown 340).

Specifically, krautrock's link to the avant-garde is undoubtedly attributed largely to the work of experimental composer Karlheinz Stockhausen (Brocker 99). Born in 1928, Stockhausen was a composer famous for pioneering the concept of "musical space." His compositions would often require sound to be amplified from various positions to create the illusion of music 
occupying a literal three dimensional space. He was also one of the earliest true innovators of electronic music with his compositions Studie I and Studie II being especially important for its development during the 1950s and 60s. As a leading avant garde figure, there is no single individual more influential on krautrock's development than Stockhausen. As a Cologne resident, he lived in the heart of Germany's then developing krautrock scene- not far from Kraftwerk's private Kling Klang studio in Düsseldorf. Of all the aspiring krautrock musicians trying to find that "new" sound, Kraftwerk founding members Ralf Hütter and Florian Schneider gleaned the most influence from Stockhausen, as they considered themselves "the second generation of electronic explorers, after Stockhausen" (Grönholm 379). With Kraftwerk, they were able to take what was at first, a niche, avant garde movement, and transform it into a wideappealing, international phenomenon. Stockhausen himself even commented on Kraftwerk, saying that "music now cannot only be sung or played on traditional instruments, but it is also possible to produce one's own sounds for a new piece. And you know how certain sounds are formed. That opens up a completely new horizon for the whole of Western music" (Schütte 8990).

\section{The Cost of Innovation}

Part of understanding the way in which Kraftwerk were able to continually innovate music technology is understanding the background of founding members Ralf Hütter and Flourian Schneider. According to former Kraftwerk musician Eberhard Kraneman, both Hütter and Schneider grew up in incredibly wealthy households with millionaire parents (Esch). The availability of lucrative financial resources was a key component in their capacity to innovate, as it was precisely this wealthy background that allowed them to afford all of the various gadgets and instruments used in their experimentation and musical production. Their wealthy background is also what most likely funded their own private Kling Klang studio too.

The idea that these average West German students could afford not only the plethora of instruments used, but their own entire recording studio in the heart of Düsseldorf, is nothing short of extraordinary unless one considers the sheer wealth that Hütter and Schneider arose from. For instance, if the price of the Minimoog Model D (a synthesizer purchased by the band during the early 1970's) was adjusted for inflation, it would cost more than $\$ 60,000$ today. Additionally, the EMS Synthi A - another staple synthesizer used by Kraftwerk - originally sold for $\$ 25,000$. The inaccessibility of these instruments cannot be overstated due to the unique financial capabilities that Kraftwerk had at their disposal. It is through this perfect culmination of creative drive and the ability to finance it that Kraftwerk were able to innovate and create something new well beyond the works of their peers.

\section{Technological and Musical Evolution}

Very little of the band's rehearsal time involved the members "playing" their instruments but rather listening to the instruments play themselves. They would repeat pre-programmed sequences and loops for hours in an attempt to blur the lines between man and machine, and a similar technique was used during album recording. Inspired by their fellow mates in German experimental rock band Can, Hütter and Schneider recognized the importance of total artistic freedom in musical creation. As Maxime Schmitt, a frequent Kraftwerk collaborator, described:

Often, they would all sit behind the console, letting the machines run by themselves for one or two hours, the sequencers, everything. From time to time Florian would stand up and go to another machine and start or launch another 
sequence. It was almost closer to a traditional jam session than to studio work.

The following day they would listen back to the tape (Bussy 100).

While there is no doubt that Kraftwerk's unorthodox recording style hugely influenced modern electronic music production, an additional aspect for which they are most frequently praised are the various pieces of technology that they utilized during their recording sessions, which were frequently shrouded in mystery and intrigue as Kraftwerk were very secretive about their creative process. From their self-titled debut Kraftwerk (1970), Kraftwerk were already incorporating self-made oscillators into their music, most prominently heard on the closing track, "Vom Himmel Hoch" (Brocker 101). Oscillators are devices that form consistent, oscillating electric signals, usually in the form of a sine or square wave. They form the basis of perhaps all modern sound synthesis techniques. Kraftwerk 2 (1971) saw the band's first usage of drum machines purely as a necessity - a necessity that would later become one of the band's major trademarks - considering they could not find a permanent drummer during this time (Brocker). This album also featured the band experimenting with different recording speeds of multiple tape recorders to produce highly synthetic, alien sounds (most notably heard on the first track, "Kling Klang").

Kraftwerk's third album, Ralf and Florian (1973), marked a transition point for the band from the early, avant-garde sound of Kraftwerk 1 and Kraftwerk 2 to the more characteristic, pop influenced sound that Kraftwerk further developed on their succeeding albums. Most importantly though, it introduced two monumental developments into Kraftwerk's sound: the usage of analog synthesizers - specifically the Minimoog Model D and the EMS Synthi A — as well as the vocoder on the song "Ananas Symphonie". Additionally, the song "Kristallo" could be seen as a precursor to techno music through its use of a drum machine coupled with a sixteenth-note bass pattern provided by the synthesizer. These technological acquisitions marked a turning point in Kraftwerk's career as according to Carsten Brocker, "they [now] had the opportunity to create music based entirely on electronically generated and modulated signals" (Brocker 103).

During the same time of Ralf und Florian's release (October 1973), Kraftwerk also unveiled a crudely built, electronic drum-kit during a live TV performance on a television show called Aspekte (Schütte). It was composed of twelve round metal plates within a silver-foil casing with what appeared to be sewing needles serving as the actual "drumsticks" to play the contraption. The kit was designed by new Kraftwerk member Wolfgang Flür; he had just joined the band following the release of Ralf und Florian. Flür's new drum-kit would later become a Kraftwerk trademark through its usage on the six succeeding albums.

By fully embracing their newfound reliance on electronic gear as well as new member Wolfgang Flür, Kraftwerk completed their transition from obscure krautrock to full-on electronic pop music with their 1974 landmark release, Autobahn. This was the first Kraftwerk album to extensively use lyrics up to this point despite only being on the title track, as previous works had primarily been instrumental (Littlejohn). Interestingly enough, Hütter has regarded the introduction of lyrics as merely an expansion of their pre-existing sound spectrum by using their voices as any other instrument (Brocker). The title track also features an extensive amount of audio-phasing and panning tricks (simulating the doppler effect heard from cars driving by on a highway), recorded tape sounds such as a car starting up as well as radio noise, and further use of the vocoder, which continued where they left off on "Ananas Symphonie" from Ralf und Florian. This culminated in a strange global occurrence in 1975: although Anglo-American music usually dominated music charts across many areas of the world, Kraftwerk's song 
“Autobahn”, a song about Germany's extensive motorway system, charted in multiple countries, including the United States, Canada, The Netherlands, New Zealand, Australia, Belgium, and Germany. Even though the track was almost twenty-three minutes in length on the album, the cut-down, radio-friendly version of song that was distributed globally was just over three minutes long.

Briefly before Kraftwerk's US tour to support Autobahn's release, the band decided to add another member to the band, deciding on classically-trained percussionist Karl Bartos to act as an additional electronic drummer, which officially made Kraftwerk a four member band (Schütte). This new lineup — consisting of Ralf Hütter, Florian Schneider, Wolfgang Flür, and Karl Bartos-became the band's definitive lineup until 1987 and is also recognized as the most iconic lineup of Kraftwerk. Following the positive reception of many aspects of Autobahn, changes were made towards commercialization for future releases. These changes included songs having more orthodox structures (often verse-chorus), lyrics were incorporated more heavily, and songs were of shorter, more digestible and radio-friendly length, distancing themselves from earlier works like the nearly eighteen-minute opus, "Kling Klang", off of the Kraftwerk 2 album.

After a very successful US tour, Kraftwerk released their fifth album Radio-Activity (1975) after retreating to their Kling-Klang studio. According to Hütter, it was a pure electronic concept album dedicated "to the age of radio and radiation at the same time" that showcased the band confronting language through clever word puns and phonetic experiments (Schütte). For example, the song "Radio Stars" implies it is about pop musicians when it is actually about quasars and pulsars. Additionally, it features the heaviest vocoder use compared to their previous albums along with three additional gear acquisitions: a Votrax speech synthesizer, an ARP Odyssey synthesizer, and an Orchestron keyboard. The Votrax speech synthesizer —often dubbed by Hütter as a 'singing typewriter' — can be heard most prominently in the song 'Uranium.' The Orchestron keyboard allowed the band to achieve polyphonic textures on a singular instrument, something they had not been able to achieve before its acquisition. During the Radio-Activity tour, the band also experimented with light-beam projections to trigger drum patterns with a device they called the "cage" (Brocker 107). However, they soon scrapped it after it malfunctioned on stage and never used it again. It was not the case that all of Kraftwerk's musical exploits were as successful as others, as Radio-Activity saw fewer albums sales than Autobahn in England and the United States, although it did find them some new fans in France and other areas of continental Europe (Griinholm). The band tried new commercial approaches on this album, such as incorporating lyrics in both English and German within individual tracks to increase broader appeal in the global market, but this approach was not well received and was largely abandoned on subsequent releases, with the band vouching to instead record both English and German versions of songs in the future (Littlejohn).

Trans-Europe Express (1977) saw the band acquiring another important piece of gear for their arsenal: the Synthanorma Sequenzer, designed by Matten \& Wiechers. A sequencer is a piece of equipment that is designed to trigger musical events at a fixed rate. This instrument allowed the band to automate much more of their playing than ever before and even featured exclusive features for the band not available to the general public at the time. It was also responsible for the more minimalist and hypnotic sound of Trans-Europe Express as every song was written specifically within the limitations of the Synthanorma Sequenzer. This sequencer is also featured on The Man-Machine (1978) along with another device designed by Matten \& Wiechers - a metal console with 6 different rows of switches used to control percussion sounds during live performances. The Man-Machine also marked the first time the band used a 
Polymoog synthesizer, which is a device somewhat akin to an electric organ. Following the album's release, it proved to be widely influential on the then-developing synthpop scene and the album is now regarded by many as one of the greatest electronic records of all time.

Arguably the last truly innovative Kraftwerk album before the band's experiments with digital technology was Computer World (1981), which showcased the band integrating their recording studio into live performances after redesigning it to be transported as modules that could be assembled onstage. This was a natural progressive step in addressing the needs of how technologically demanding Kraftwerk's music had become. Due to the increased complexity in sound, the exact instrumentation of this album is largely unknown (Brocker). However, according to Brocker, the band in fact used several non-musical appliances during recording sessions including "a Casio pocket calculator, a Dübreq Stylophone, a Bee Gees Rhythm Machine toy keyboard by Mattel, and voice-producing appliances from Texas Instruments" (Brocker 111), This complimented Computer World's themes which dealt highly with mankind's increasing reliance on technology.

Following Computer World's success, Kraftwerk only released two further albumsElectric Café (1986) and Tour de France Soundtracks (2003) — which aren't as innovative as the band's prior releases. Electric Café was criticized because the band applied a more commercial approach to songwriting, which caused the music to be perceived by consumers as more sterile, less engaging, and devoid of over-arching album themes that were present on and played a role in the cohesiveness of previous works, especially in the case of Electric Café (Littlejohn). Part of the reason for these criticisms was that Electric Café (and the Tour de France Soundtracks album too) was composed using predominantly digital technology, unlike their past releases which utilized analog gear. Furthermore, the band took an extensive hiatus in the years before Electric Café was released, which caused the band to lose momentum and caused music consumers to lose enthusiasm. Additionally, Electric Café would be the first Kraftwerk album to not feature prominent member Wolfgang Flür since 1972's Kraftwerk 2. There was another extended hiatus prior to the release of Tour de France Soundtracks, which was released as a way of celebrating the 100 anniversary of the Tour de France bicycle races. Kraftwerk, and in particular, Ralf Hütter, were avid cyclists. Tour de France Soundtracks departed from the practice of releasing albums in both English and German, and instead released one version of the album that incorporated lyrics in English, German, and French. On the world tour that followed, the band performed songs from four laptops using sampling, sequencing, and synthesizer software, which was a noted departure from previous live shows that featured more musical equipment and analog instrumentation. Tour de France Soundtracks was the highest charting album of the band's career and was a critical success due largely to the hype surrounding the return of a long dormant band that was regarded as trailblazing and classic at the time.

\section{The Legacy}

Despite inconsistency in the reception of their later output, Kraftwerk left a permanent mark on the music industry and played a pivotal role in the development of a uniquely German cultural identity. By pioneering electronic pop at a conceptual level, Kraftwerk achieved a level of fame and influence comparable only to that of The Beatles (Schütte, 2020). As noted by Cohen, many of the world's top music critics list at least one of Kraftwerk's albums among their favorite and most influential albums of all time. They single-handedly innovated technology's role in music composition through blurring the lines between man vs. machine through the synthesis of both and the creation of new musical hardware. Because of the futuristic, technological vision of two 
young German students - Ralf Hütter and Florian Schneider - and their desire to create something whole-heartedly new, the state of music technology rapidly advanced which influenced countless other musicians on an international level, including many artists within Detroit techno, electro-pop, rap, and hip-hop (Seago, Vincent). One of the easiest influential trajectories to draw is from Kraftwerk's use of the vocoder to today's widespread use of autotune technology (Shahan). Virtually all music that utilizes electronic instruments has something to owe to Kraftwerk's legacy with everything from techno to modern trap music applying it. Additionally, they helped lay the framework for electronic pop music with artists like Depeche Mode, Soft Cell, and The Human League later expanded upon it with the development of the British synthpop scene. Kraftwerk were even influential for genres like hip-hop as DJ producer Afrika Bambaataa and his group Soulsonic Force released a single called 'Planet Rock' which sampled the Kraftwerk songs 'Numbers' and 'Trans-Europe Express' to create a fusion of electro and funk in 1988. This song single-handedly started the genre later to be known as "electro-funk" and helped further plant the seeds for hip-hop's later success in the 1990's (Toltz). Despite the more obvious aforementioned influences, their influence extended into other musical genres beyond those that clearly utilized elements of Kraftwerk's music. Artists that have specifically listed Kraftwerk as an influence include David Bowie, Depeche Mode, Duran Duran, Iggy Pop, Jay-Z, Moby, and Joy Division (Cohen). Another way of seeing the expansive range of influence that Kraftwerk had is to look at the many covers of their songs that exist across many dissimilar genres, with artists as disparate as the comedian Rick Moranis, Irish rock band U2, British rock band Coldplay, the Faux Latino band Señor Coconut, the Italo disco group Koto, the Japanese noise-rock band Melt-Banana, similarly influential Germanic metal band Rammstein, and the Dutch death metal band Gorefest all having offered their own interpretations of some of Kraftwerk's most seminal works.

Kraftwerk is a band that has received ongoing academic attention, and rightfully so, as they've played a pivotal role in influencing popular and indie music; they were innovators in their use and creation of novel technologies; and they helped Germanic youth form a sense of postwar identity that was uniquely Germanic but that marked a clear departure from the ways of Germany's more shrouded past.

\section{Funding}

This work was not funded by a grant of funding agency.

\section{Disclosure Statement}

The authors of this manuscript do not have any potential conflicts of interest.

\section{Biographical Note}

Scott Shannon studies musical education at University of Houston and is an active synth and noise musician under the moniker "Psilosergic." He has an ongoing interest in musical technology of all kinds with an emphasis on vintage, analog gear.

Kyle J. Messick is a social psychologist that specializes in metal music studies and religious studies. He is an advocate for open science practices and has had works published in multiple books, including by publishers Routledge and Brill. 


\section{Works Cited}

Adelt, Ulrich. "Machines with a heart: German identity in the music of Can and Kraftwerk." Popular Music and Society, vol. 35, no. 3, 2012, pp. 359-374. doi: 10.1080/03007766.2011.567908

Barr, Tim. Kraftwerk: from Dusseldorf to the Future With Love. Random House, 2013.

Brocker, Carsten. "Kraftwerk: Technology and Composition." Trans. Michael Patterson. In Kraftwerk: Music Non-Stop, ed. Sean Albiez and David Pattis, 2011, pp. 97-118.

Brown, Timothy Scott. "In search of space: the trope of escape in German electronic music around 1968." Contemporary European History, vol. 26, no. 2, 2017, pp. 339-352. doi: 10.1017/S0960777316000606

Bussy, Pascal. Kraftwerk: Man, Machine and Music. SAF Publishing Ltd, 2004.

Cohen, Bruce. "Technology, Popular Culture and Kraftwerk." In Being Cultural, Pearson: New Zealand, 2012, pp. 273-286.

Cope, Julian. Krautrocksampler: One Head's Guide to the Great Kosmische Musik - 1968 Onwards. United Kingdom: Head Heritage, 1995.

Della Porta, Donatella. "Protest, protesters, and protest policing: Public discourses in Italy and Germany from the 1960s to the 1980s." In How social movements matter, University of Minnesota Press, 1999, pp. 66-96.

Esch, Rudie. Electri_City: The Düsseldorf School of Electronic Music. London: Omnibus Press, 2016.

Griinholm, Pertti. "Kraftwerk-the Decline of the Pop Star." Kraftwerk-Music Non-Stop. Ed. by Sean Albiez and David Pattie. London and New York, 2011, pp. 63-79.

Grönholm, Pertti. "When Tomorrow Began Yesterday: Kraftwerk's Nostalgia for the Past Futures," Popular Music \& Society, vol. 38, no. 3, 2015, pp. 372-388. doi: 10.1080/03007766.2014.969034

Littlejohn, John T. "Kraftwerk: Language, Lucre, and Loss of Identity.” Popular Music and Society: Krautrock, vol. 32, no. 5, 2009, pp. 635-653. doi: 10.1080/03007760903251441

Messick, Kyle J., Blanca Aranda, and Chris Day. The experiences of metal fans with mental and developmental disorders in the metal music community. Metal Studies Studies, vol. 6, no. 2, 2020, pp. 193-214. doi: 10.1386/mms_00013_1

Messick, Kyle J. and Blanca E. Aranda. "The role of moral reasoning \& personality in explaining lyrical preferences.” PLOS ONE, vol. 15, no. 1, 2020, e0228057. doi:10.1371/journal.pone.0228057

Pattie, David. 'Introduction: The (Ger)man machines', Kraftwerk - Music Non-Stop. Ed. by Sean Albiez and David Pattie. London and New York, 2011.

Seago, Alex. The "Kraftwerk-Effekt": Transatlantic circulation, global networks and contemporary pop music. Atlantic Studies, vol. 1, no. 1, 2004, pp. 85-106. doi: 10.1080/1478881042000217214

Schiller, Melanie. "Fun Fun Fun on the Autobahn": Kraftwerk Challenging Germanness. Popular Music and Society, vol. 37, no. 5, 2014, pp. 618-637. doi: 10.1080/03007766.2014.908522

Schütte, Uwe. Kraftwerk: Future Music from Germany. London: Penguin Books, 2020.

Shahan, Cyrus. "The Birth of Autotune and the Loop of (West) German Identity." German Politics and Society, vol. 35, no. 2, 2017, pp. 7-25. doi: 10.3167/gps.2017.350202 
Toltz, Joseph. "'Dragged into the Dance' - the Role of Kraftwerk in the Development of Electro-Funk," in Kraftwerk: Music Non-Stop, eds. Sean Albiez and David Pattie, New York: Continuum, 2011, 181.

Vincent, Rickey. "Hip-Hop and Black Noise: Raising Hell.” In Forman, Murray. \& Neal, Mark Anthony's That's the Joint! The Hip-Hop Studies Reader. Routledge, 2004, pp. 481-492. 